\title{
Consórcio de educação de Barcelona: evidências de gestão compartilhada de serviços educativos via consórcios públicos ${ }^{1}$
}

\author{
Consortium of education of Barcelona: evidence of shared management of \\ educational services via public consortia \\ Consorcio de educación de Barcelona: evidencias de gestión compartida de \\ servicios educativos vía consorcios públicos

\section{THAMARA CAROLINE STRELEC VALERIANO MENDES FERREIRA COSTA RAQUEL GALLEGO CALDERON}

\begin{abstract}
Resumo: Partindo da inexistência no Brasil de consórcios públicos exclusivamente de educação nos termos da Lei de Consórcios Públicos (Lei n 11.107/2005), este artigo toma como referência o Consórcio de Educación de Barcelona, experiência única na Espanha de gestão compartilhada de redes públicas de ensino entre governos, com o objetivo de compreender seu modelo de gestão e identificar seus resultados e desafios. Por meio de um estudo de caso, constataram-se limitações para a implementação de programas e desafios oriundos das preferências e herança dos governos, embora o consórcio tenha permitido a superação de problemas na cobertura da rede de atendimento e de sobreposições na gestão.
\end{abstract}

Palavras-chave: Cooperação intergovernamental, Consórcios Públicos, Consórcio de Educação, Políticas Públicas Educacionais.

\begin{abstract}
Based on the lack of public consortiums under the Public Consortia Law (Law $\left.n^{\circ} 11.107 / 2005\right)$ exclusively of education in Brazil, this article takes as reference the Barcelona Education Consortium, a unique experience in Spain of shared management of public education networks between governments, with the objective of understanding its management model and identifying its results and challenges. Through a case study, limitations were found for the implementation of programs and challenges arising from the preferences and inheritance of the governments, although it allowed the overcoming of problems in the coverage of the service network and overlaps in the management.
\end{abstract}

Keywords: Intergovernmental cooperation, Public Consortia, Education Consortium, Public Educational Policies.

\footnotetext{
1 Este artigo foi elaborado durante o estágio doutoral realizado pela primeira autora no l'Institut de Govern i Politiques Publiques da Universidad Autònoma de Barcelona, sob orientação da Prof.. Dra. Raquel Gallego Calderon e do Prof. Dr. Valeriano Mendes Ferreira Costa. Apresenta parcialmente os resultados do projeto "Cooperação intergovernamental para a prestação de serviços educacionais: um estudo do Consórcio de Educação de Barcelona", realizado com apoio e financiamento da Fundação de Amparo à Pesquisa do Estado de São Paulo (FAPESP), processo n ${ }^{\circ}$ 2015/25354-5. As opiniões, hipóteses e conclusões ou recomendações expressas neste material são de responsabilidade do autor e não necessariamente refletem a visão da FAPESP/ CAPES.
} 
Resumen: Partiendo de la inexistencia en Brasil de consorcios públicos exclusivamente de educación, bajo la Ley de Consórcios Públicos (Ley $\mathrm{n}^{\mathrm{o}}$ 11.107/2005), este artículo toma como referencia el Consorcio de Educación de Barcelona, experiencia única en España de gestión compartida de redes públicas de enseñanza entre gobiernos, con el objetivo de comprender su modelo de gestión e identificar sus resultados y desafíos. Por medio de un estudio de caso, se constataron limitaciones para la implementación de programas y desafíos oriundos de las preferencias y de la herencia de los gobiernos, aunque el consorcio haya permitido la superación de problemas en la cobertura de la red de atendimiento y de sobreposiciones en la gestión.

Palabras clave: Cooperación intergubernamental, Consorcios Públicos, Consorcio de Educación, Políticas Públicas Educativas.

\section{INTRODUÇÃO}

No campo da administração pública, o estabelecimento ascendente de soluções intergovernamentais com viés cooperativo tem implicado a crescente elaboração de estudos sobre formas de cooperação intergovernamental adotadas nos países, tais como os casos brasileiro (ABRUCIO, 2012; CALDAS, 2007; STRELEC, 2016; 2017), suíço e canadense (BOLLEYER, 2009), estadunidense (FEIOCK, 2013; WILSON; GAMKHAR, 2011) e europeu (HULST; MONFORT, 2007).

Os consórcios públicos, comumente intermunicipais ou interlocais, são um tipo específico de acordo governamental para lidar com políticas que demandam esforço conjunto para a ampliação da capacidade de gestão dos serviços públicos, dirimir externalidades negativas ou viabilizar ganhos de escala e efetividade da política (CARNEIRO; DILL, 2012).

No Brasil, principalmente em função da política de saúde e da Lei 11.107/2005, que regulamentou o funcionamento de consórcios públicos, estimase a existência de pelo menos 700 consórcios (STRELEC, 2017) e, embora a legislação seja flexível, consórcios públicos têm atuado sobremaneira em políticas de saúde, meio ambiente, infraestrutura e desenvolvimento.

A esse respeito, consórcios públicos têm lançado mão de estruturas de governança para o desenvolvimento de ações educacionais como Câmaras Técnicas, Grupos de Trabalho, Núcleos Técnicos ou Colegiados; contudo, consórcios exclusivos para a gestão de políticas educacionais não se evidenciam 
na realidade brasileira ${ }^{2}$ (STRELEC, 2017), colocando dúvidas sob os ombros de pesquisadores e formuladores de políticas a respeito de sua operabilidade na educação, dos potenciais ganhos de escala na aquisição dos insumos escolares e qualidade na oferta desse serviço e, ainda, como os ganhos constatados em consórcios nas demais áreas se aplicariam ao contexto educacional (ARAÚJO, 2012; GANZELI; OLIVEIRA, 2013; ABICALIL, 2013).

Além disso, na esteira das discussões em âmbito nacional sobre regime de colaboração e de potenciais mecanismos de gestão que o colocariam em prática, há um esforço no âmbito do governo federal, comunidade científica e movimentos organizados por entidades fundacionais em compreender as potencialidades de consórcios e outros mecanismos de cooperação para a melhoria dos serviços educacionais e promoção da articulação entre as redes de ensino (MOVIMENTO COLABORA, 2017).

Assim como no Brasil e em muitos países, na Espanha, os governos locais recorrem a consórcios para promover articulação intergovernamental. Contudo, enquanto no Brasil não há referência de consórcios públicos estabelecidos nos termos da Lei de Consórcios Públicos exclusivos ao desenvolvimento de políticas educacionais, na Espanha, país no qual os consórcios se desenvolveram com ênfase na década de 90 (PRATES, 2010), está em funcionamento desde 2002 uma experiência única de consorciamento nesses moldes, o Consórcio de Educação de Barcelona, constituído entre o governo da Comunidade Autônoma da Catalunha (Generalitat da Catalunha) e do município de Barcelona (Ayuntamiento de Barcelona), com o objetivo comum de "[...] avançar para a gestão integrada da educação da cidade, sob os princípios de proximidade e eficiência, para melhorar os níveis de excelência e equidade [...]. O Consórcio é portanto interlocutor único para atender as necessidades dos centros educacionais e das famílias da cidade" (CONSORCI D'EDUCACIÓ DE BARCELONA, 2009, p.1)³.

Essa singularidade e, especialmente, o fato de o Consórcio de Barcelona se dedicar ao planejamento e à gestão de redes de ensino a partir da gestão compartilhada entre níveis de governo distintos suscita as perguntas: qual o

Considera-se nesta afirmação, a inexistência de experiências que configurem a criação de uma terceira personalidade jurídica, denominada consórcio público, com caráter jurídico de direito público, estabelecida entre municípios, estados ou União por meio de procedimentos legais previstos na lei e que explicitem exclusivamente objetivos voltados à promoção de iniciativas voltadas à educação. Embora o termo consórcio tenha sido adotado anteriormente à lei a que este artigo faz referência, como é o caso de consórcios de universidades ou consórcios de municípios, os dispositivos empregados para a formalização de parcerias entre as instituições do setor público - dentre elas as universidades - são os convênios (SOUZA, 2013), ou, no caso de parcerias de municípios, o estabelecimento de associações civis de direito privado (STRELEC, 2011).

3 [...] d'avançar cap a una gestió integrada de l'educació de la ciutat, sota els principis de proximitat i eficàcia, per millorar-ne els nivells d'excel lència i d'equitat.[...]. El Consorci és, doncs, l’interlocutor únic per atendre les necessitats dels centres educatius i les famílies de la ciutat (tradução nossa). 
desenho organizacional e os mecanismos de gestão adotados para integrar a gestão da política dos dois níveis de governo? Quais os resultados e desafios da gestão compartilhada a partir do consórcio?

Norteando-se por estes questionamentos, este artigo objetiva compreender o funcionamento do Consórcio de Educação de Barcelona e identificar seus principais resultados e desafios no exercício compartilhado das competências em matéria educacional. Em se tratando de uma experiência única, ainda sem registro nas bases de dados Scielo, Portal Capes Periódicos e Educ@ da Fundação Carlos Chagas, trata-se se uma referência analítica de elevada importância por seu ineditismo e potencial de responder a questões oriundas do contexto brasileiro, guardadas as diferenças político-institucionais entre os dois países.

Em termos metodológicos, este artigo resulta de um estudo de caso que envolveu um conjunto de instrumentos de coleta de dados: revisão bibliográfica, análise documental e de publicações da entidade, revisão do ordenamento jurídico que embasou sua formação e, ainda, entrevistas com gestores e representantes do Conselho de Direção de ambos níveis de governo, coleta de dados, fundamental para o acesso a documentos, e compreensão dos aspectos político-institucionais que perpassam a entidade 4 .

Para a apresentação dos resultados, este artigo está composto de cinco seções, além desta introdução. A primeira, apresenta os antecedentes históricoinstitucionais que culminaram na criação do Consórcio de Educação de Barcelona, para na segunda seção, ser apresentada a estrutura de governança e gestão adotada pela entidade. Na terceira, são apresentados os resultados da análise dos balanços e processos decisórios que perpassam a gestão financeira e orçamentária do CEB para na quarta seção descrever as principais mudanças promovidas pelo consórcio com a gestão compartilhada. Finalmente, nas considerações finais, este artigo responde aos questionamentos levantados nesta introdução, apresentando uma análise do conjunto de informações obtidas com o estudo.

\footnotetext{
4 Foram entrevistados: Berta Argany Moya, gestora responsável pelo gabinete da Gerência; Manel BLASCO, ex-gerente responsável pela implantação da entidade; Miguel Angel Essombra, Comissionat d’Educacio $\square$ e representante do Ayuntamiento de Barcelona no consórcio; Maria Jesús Mier Albert, Secretária Geral do Departamento de Ensino da Generalitat da Catalunha e Presidente do Conselho de Direção; Ignasi Fernández, responsável pela Direção de Recursos e Pere Masó Anglada, representante da área de serviços de Educação e Território.
} 


\section{ANTECEDENTES E CONSTITUIÇÃO}

O Estado Autonômico espanhol é um sistema de governo com um desenho peculiar, composto por uma unidade central de governo - Governo Central - e vinte e sete Comunidades Autônomas (CCAA), organismos que dispõem de um ordenamento jurídico distinto, que define as condições nas quais as políticas públicas serão executadas (GARRIDO, 2007). Esse modelo favoreceu a criação de diferentes entidades de cooperação, sendo as principais as mancomunidades, áreas metropolitanas e consórcios administrativos, estes últimos estabelecidos por acordos voluntários entre autoridades locais, Comunidades Autônomas e Estado, e com menor frequência, entidades privadas sem fins lucrativos (HULST; MONFORT, 2007).

Especificamente no caso da Comunidade Autônoma da Catalunha (CAC), o município de Barcelona, sua capital, obteve em 1998, por intermédio da Carta Municipal de Barcelona (CMB $)^{5}$ autonomia e competências em um conjunto de políticas públicas. Esta condição envolveu intenso processo de diálogo com as forças políticas dos níveis autonômico e central em torno da resolução de como competências até então exclusivas da CAC seriam "transferidas" ao município de Barcelona sem implicar prejuízo para o governo autonômico no processo de definição e implementação das políticas públicas.

Esse processo culminou na conformação de consórcios inspirados nos consórcios administrativos, denominados consórcios públicos legais, que apresentam a particularidade de não se tratarem de um arranjo oriundo exclusivamente da vontade de colaborar dos governos, mas também, de uma determinação legal para a criação e efetivação de um modelo compartilhado de competências em diversas áreas. Desse modo, foram constituídos pela CMB consórcios de Habitação, Serviços Sociais e Educação, inaugurando um novo modelo de distribuição de competências entre níveis de governos que até então figuravam uma relação hierarquizada no mesmo território (STRELEC, 2016).

Portanto, o Consórcio de Educação de Barcelona (CEB) é um dos consórcios legais formalizados entre os níveis de governo atuantes no território que compreende os dez distritos que constituem o município de Barcelona - Generalitat da Catalunya e o Ayuntamento de Barcelona, o mesmo que tem como finalidade cogestionar os serviços educacionais até então desempenhados de maneira separada entre as duas instâncias de governo (BLASCO, 2002). 
Embora sua constituição tenha sido aprovada em 1998, a aprovação de seu estatuto ocorreu em 2002. Entretanto, a implantação institucional iniciou-se em 2005, até sua efetivação em 2009 como entidade gestora única dos centros educativos, processo que envolveu, sobretudo, a delegação de competências dos serviços educativos dos dois organismos de governo ao CEB.

Até a criação do CEB, o Ayuntamiento de Barcelona era responsável pela cessão de terrenos para a construção de escolas, pelos Conselhos Escolares e acompanhamento dos serviços educacionais executados pela CAC, responsável pela gestão das escolas que integram a oferta de educação pública primária e secundária (BLASCO, 2002), e de forma complementar, o governo municipal de Barcelona contava com uma rede própria na cidade, composta por escolas de ensino infantil (escolas bressoh), música, ensino complementar, além de programas e um Instituto Municipal de Educação.

A atuação de dois governos no mesmo território implicava duplicidade de esforços e descoordenação, além de concorrência entre as administrações, em função das duas redes (autonômica e municipal); portanto, o objetivo principal da criação do CEB foi melhorar a gestão educacional e aproximá-la dos cidadãos, por intermédio de uma estratégia de corresponsabilidade (BLASCO, 2002).

No que se refere à gestão, o CEB assumiu a responsabilidade de promover mudanças que evidenciassem os aspectos locais. Nesse cenário, o município de Barcelona, uma vez dotado de autonomia e autoridade para o exercício de competências, foi inserido em decisões nas quais cumpria papel auxiliar. A este respeito, Argany, gestora responsável pelo gabinete da Gerência do CEB, destacou que "quem tem mais a ganhar com o consórcio é o município. Porque quem tem a competência da educação é o governo autonômico". Complementar a essa percepção, coexiste a visão otimista da gestão compartilhada:

\footnotetext{
Barcelona tem um impacto e volume de centros educativos muito importante, [...] e pensaram que seria melhor consensuar e ir juntos do que fazê-lo à parte. $\mathrm{O}$ sistema de Barcelona continua funcionando, mas podem ter percebido que seria possível ganhar mais se administramos juntos (entrevista, concedida por Argany em 25/04/2016).
}

$\mathrm{O}$ escopo do $\mathrm{CEB}$ está vinculado às competências definidas nos artigos 123 e 124 da CMB, que se referem à gestão dos serviços educacionais, com exceção daqueles voltados ao ensino superior e a currículo: planejamento e distribuição territorial dos centros docentes; criação, construção e obras de reforma, ampliação e melhoria dos centros; gestão dos programas de proteção social, formação profissional, centros de regime especial e educação de adultos, educação complementar e extraescolar; criação e gestão de centros pedagógicos 
e recursos, serviços de apoio, assessoramento, avaliação psicopedagógica e formação docente; programas de educação compensatória a alunos em situação de desvantagem social, minorias étnicas, imigrantes e famílias com graves dificuldades socioeconômicas; vigilância do cumprimento da escolaridade obrigatória; regulamentação e gestão do transporte, merenda; garantia de atuação de um órgão de inspeção ${ }^{6}$ e prestação de contas (GENERALITAT DA CATALUNYA, 1998).

A implantação da gestão compartilhada envolveu em 2008 a transferência da gestão de trinta e um centros educacionais do município ao $\mathrm{CEB}$, suprimindo as atividades da entidade até então responsável ${ }^{7}$. Além disso, a Generalitat da Catalunha transferiu a gestão de 256 escolas de sua titularidade ao CEB. Desse modo, profissionais das escolas públicas municipais (docentes e pessoal administrativo) passaram a ser geridos pelo CEB, conforme a Figura 1:

\section{Figura 1: Rede escolar assumida pelo Consórcio de Educação de Barcelona em 2009}

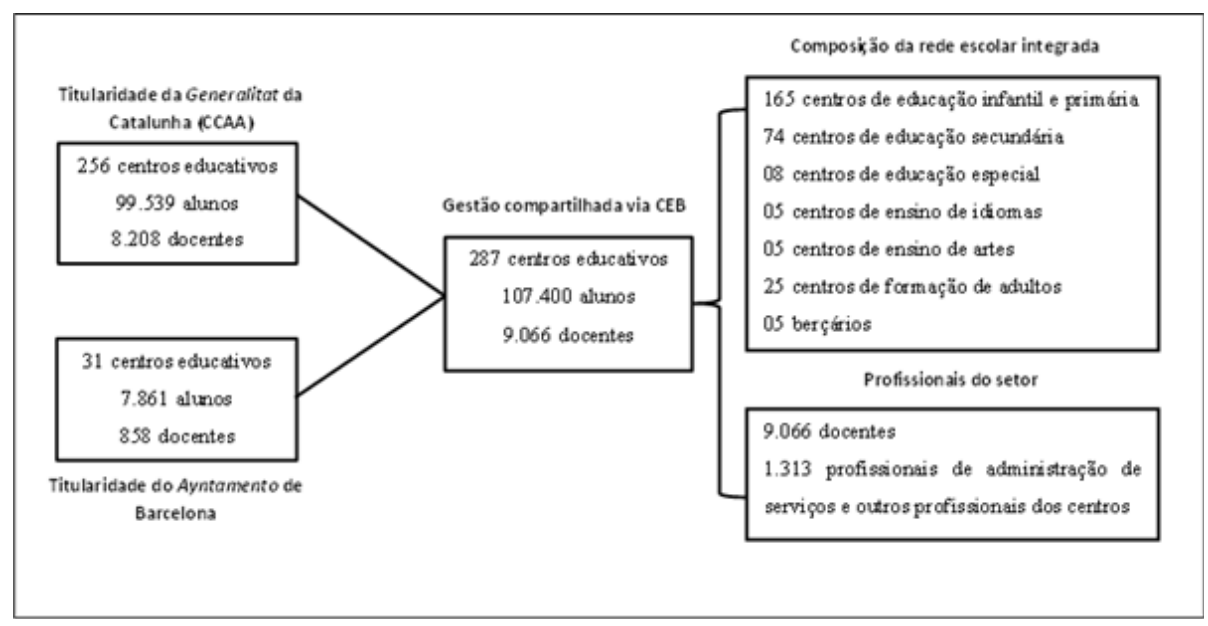

Fonte: Elaboração da autora, com base em Consorci d'Educació de Barcelona (2009).

Para a execução da gestão compartilhada, o CEB elabora e aprova anualmente um plano de trabalho que define os compromissos e a linha de atuação a serem executados no ciclo educativo posterior. O plano especifica as

\footnotetext{
6 Inspeção técnica educativa.

7 Serviços Territoriais de Barcelona.
} 
estratégias e metas, sendo disponibilizado no início do ano um memorial com os resultados, a evolução do quantitativo de alunos e docentes, dos programas, execução orçamentária, reformas e construção de centros educativos.

\section{ESTRUTURA DE GOVERNANÇA E GESTÃO}

O CEB possui duas instâncias de ação: Conselho Diretivo e Conselho de Gestão, compostos por funcionários indicados pelos dois governos: Presidente, Vice-Presidente, cinco representantes da Generalitat da Catalunha, três representantes do Ayuntamiento de Barcelona, um inspetor e um secretário, responsáveis pelo suporte ao Conselho.

O Conselho Diretivo, com caráter político, delibera mensalmente sobre a nomeação dos cargos de Direção, orçamento, atribuição e delegação de competências, normas, modificação estatutária ou questões relacionadas ao patrimônio da entidade. A estrutura executiva é composta por profissionais com perfil técnico-gerencial, responsáveis pela gestão da rede escolar, e que têm na Gerência o profissional responsável pela emissão de relatórios, elaboração de indicadores e memoriais, informações que para Argany, apoiam as decisões do Conselho de Direção. Apesar desse embasamento objetivo, a convivência de duas instâncias implica dificuldades nos processos de tomada de decisão:

\footnotetext{
Nosso órgão de discussão política é o Conselho de Direção, e isso não é fácil. O Conselho tem que tomar decisões a respeito de assuntos que às vezes não estão muito claros para as duas administrações, mas estão delegadas a consensos. O positivo é que apesar das diferenças políticas e de prioridades, as duas administrações estão obrigadas a pensar Barcelona desde o Consórcio por outra ótica. (entrevista, concedida por Argany em 25/04/2016).
}

O processo de decisão do Conselho de Direção é considerado rápido e um facilitador é o trabalho consultivo desenvolvido pela gerência: "Antes de levar uma proposta para votação, queremos saber o que pensa um, o outro e ver onde há pontos médios”, destacou Berta Argany. Esse papel de relações institucionais também ocorre com instituições externas, sindicatos e associações de representação cidadã.

Embora indicados pelas duas administrações, seus membros são funcionários públicos das equipes de governo com atuação em direitos sociais, planejamento, gestão escolar, participação popular, educação básica, universitária e secundária; e a análise das nomeações no período 2007 a 2011 revelou que a média de permanência desses no Conselho é de 33 meses, e dos 23 membros 
considerados no cálculo, apenas dois permaneceram por menos de um ano, sendo que o consórcio contou durante todo seu período de constituição com dois gerentes.

Desde o início das atividades, a estrutura organizacional do CEB sofreu adaptações. Sua distribuição funcional, aprovada em janeiro de 2016 (Figura 2) encontra-se em fase de implantação, o que tem implicado ajustes e acomodação de profissionais em áreas funcionais até então inexistentes.

\section{Figura 2: Estrutura executiva do Consórcio de Educação de Barcelona} (2016)

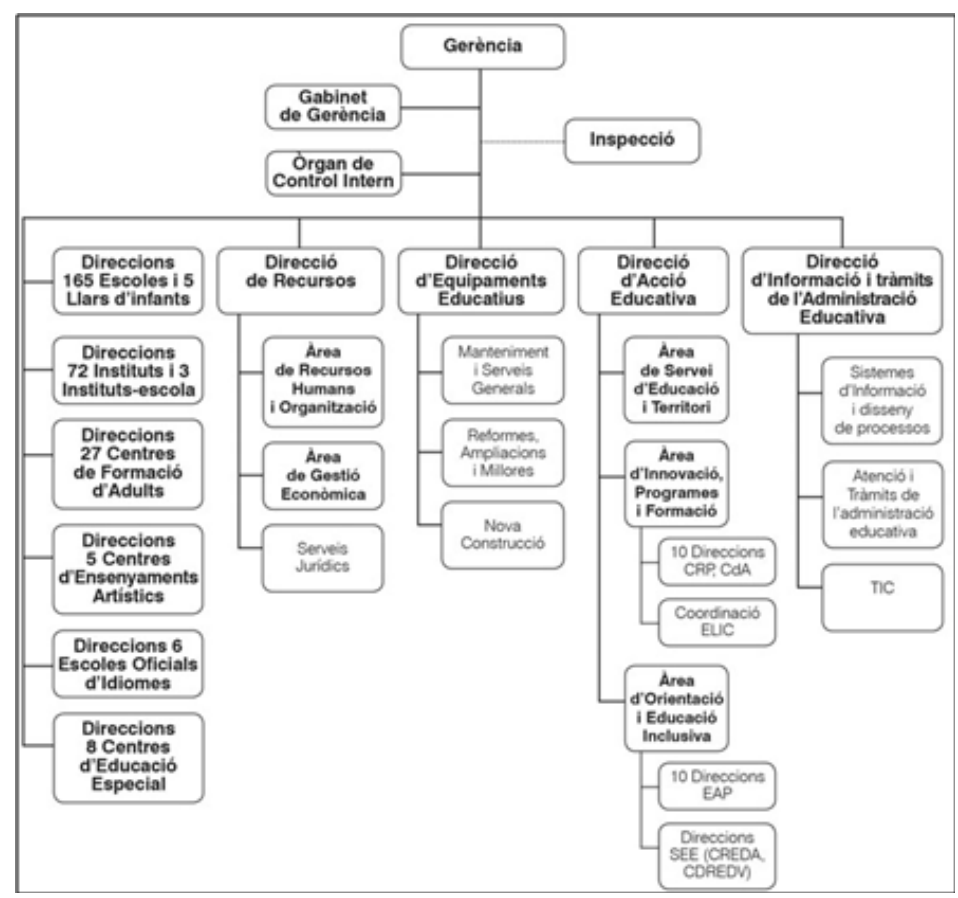

Fonte: CONSORCI D’EDUCACIÓ DE BARCELONA (2012-2016).

Comparando o primeiro organograma (2009-2010) com os subsequentes, observa-se: a) inclusão de um órgão de controle interno; b) redução de cargos de direção no segundo organograma e ampliação para cinco diretorias no atual; c) ampliação de áreas funcionais e escala hierárquica, em contraposição a uma estrutura mais enxuta; d) inclusão de direções para níveis educativos; e) linha de 
comunicação entre Gerência e Inspeção, e; f) manutenção de um organograma vertical representado por áreas funcionais (CONSORCI D’EDUCACIÓ DE BARCELONA, 2009; 2012; 2013; 2014; 2015; 2016).

A gestão de turno tem buscado garantir ao consórcio um desenho próprio, redistribuindo os profissionais entre áreas educacionais e gestão para promover descentralização funcional e otimização dos processos. Tais mudanças foram necessárias, já para conforme salientou a gerente do CEB, os organogramas iniciais foram concebidos "à imagem do Departamento de Ensino da Generalitat" e suas áreas funcionais, na medida em que foram transferidas todas suas funções, atividades e profissionais, o que demandou, inclusive, a relação entre o Conselho Diretivo e a Inspeção Educativa, haja vista que a definição das prioridades para cada distrito - com base em suas especificidades - gera um plano de trabalho que deve ser aprovado pela Inspeção, mas executado pelo CEB. Portanto, buscouse evitar desencaixes provocados pela ausência de alinhamento entre os dois organismos.

\section{GESTÃO FINANCEIRA}

A CMB não especificou a contribuição orçamentária dos governos para o financiamento das atividades do $\mathrm{CEB}$, mas o estatuto estabeleceu que "as contribuições feitas pelas entidades consorciadas devem ser pelo menos iguais ao orçamento definido com o mesmo propósito no exercício anterior para o desenvolvimento das respectivas competências" (GENERALITAT DE CATALUNYA, 2002)

Tabela 1: Previsão anual de receitas e despesas CEB (2009)

\begin{tabular}{|c|c|c|}
\hline Categoria de despesa & \multicolumn{2}{|c|}{ Valor (em euros) } \\
\hline Professores e outros profissionais & \multicolumn{2}{|c|}{413.249 .902} \\
\hline Conservação, manutenção e limpeza & \multicolumn{2}{|c|}{37.490 .692} \\
\hline Gestão escolar & \multicolumn{2}{|c|}{19.319 .483} \\
\hline Subsídios, bolsas de estudos e transporte escolar & \multicolumn{2}{|c|}{9.662 .060} \\
\hline Formação e inovação educativa & \multicolumn{2}{|c|}{4.743 .678} \\
\hline Investimentos em tecnologia, mobiliários e outros & \multicolumn{2}{|c|}{2.704 .655} \\
\hline Esfera de governo & Repasse de recursos previsto & $(\%)$ \\
\hline Generalitat da Catalunha & 428.670 .470 & 88,0 \\
\hline Ajuntament de Barcelona & 58.500 .00 & 12,0 \\
\hline Total & 487.170 .470 & 100,0 \\
\hline
\end{tabular}

Fonte: CONSORCI D’EDUCACIÓ DE BARCELONA (2009). 
Adiante, na Tabela 2, é apresentada a evolução orçamentária do consórcio no período 2010-2015:

\section{Tabela 2: Evolução da previsão orçamentária inicial de receitas correntes} CEB (2010-2015)

\begin{tabular}{|c|c|c|c|c|c|c|}
\hline \multirow{2}{*}{$\begin{array}{c}\text { Fonte de } \\
\text { receita }\end{array}$} & \multicolumn{6}{|c|}{ Receitas correntes (em euros) por ano do exercício } \\
\cline { 2 - 7 } & $\mathbf{2 0 1 0}$ & $\mathbf{2 0 1 1}$ & $\mathbf{2 0 1 2}$ & $\mathbf{2 0 1 3}$ & $\mathbf{2 0 1 4}$ & $\mathbf{2 0 1 5}$ \\
\hline $\begin{array}{c}\text { Generalitat da } \\
\text { Catalunha }\end{array}$ & 76.448 .160 & 72.062 .451 & 67.461 .976 & 61.500 .000 & 61.500 .000 & 63.836 .353 \\
\hline $\begin{array}{c}\text { Ayuntamiento } \\
\text { de Barcelona }\end{array}$ & 50.415 .385 & 58.450 .069 & 60.730 .875 & 57.995 .971 & 58.261 .183 & 59.561 .178 \\
\hline $\begin{array}{c}\text { Outros } \\
\text { ingressos }\end{array}$ & 1.743 .715 & 1.320 .000 & 1.521 .587 & 1.500 .000 & 2.000 .000 & 2.000 .000 \\
\hline Total & 128.607 .260 & 131.832 .520 & 129.714 .438 & 120.995 .971 & 121.761 .183 & 125.397 .531 \\
\hline
\end{tabular}

Fonte: CONSORCI D’EDUCACIÓ DE BARCELONA (2012 - 2016).

Observa-se que o orçamento inicial do CEB para o ano de 2010 (Tabelas 2 e 3) foi significativamente inferior ao previsto na conclusão da transferência plena da gestão (Tabela 1): o valor correspondente à Generalitat na dotação para o ano de 2010 (receitas correntes e receitas de capital) representou a soma de 80.963.860 euros e não 428.670.470 euros conforme previsto. O que justificou essa redução foi a não transferência ao orçamento de grande parcela dos profissionais da educação provenientes da Generalitat, principalmente professores.

Outra observação é que, em termos de evolução orçamentária das despesas correntes, os dois governos evolucionaram para uma relativa paridade. Em 2010, a diferença entre os valores aprovados foi de 26.032.775 euros em favor do governo da Generalitat, enquanto para o ano de 2015, essa diferença reduziuse para 4.275.175 euros. A dotação orçamentária de receitas de capital (Tabela 3) também decresceu e esse impacto se deve à redução da dotação por parte do Ayuntamiento, órgão com maior participação nas receitas para investimentos no CEB. 
Tabela 3: Evolução do orçamento inicial de receitas de capital CEB (20102015)

\begin{tabular}{|c|c|c|c|c|c|c|}
\hline \multirow{2}{*}{ Fonte de receita } & \multicolumn{6}{|c|}{ Receitas de capital (em euros) por ano do exercício } \\
\cline { 2 - 7 } & $\mathbf{2 0 1 0}$ & $\mathbf{2 0 1 1}$ & $\mathbf{2 0 1 2}$ & $\mathbf{2 0 1 3}$ & $\mathbf{2 0 1 4}$ & $\mathbf{2 0 1 5}$ \\
\hline $\begin{array}{c}\text { Generalitat da } \\
\text { Catalunha }\end{array}$ & 4.515 .700 & 3.514 .464 & 1.500 .000 & 1.500 .000 & 1.500 .000 & 1.500 .000 \\
\hline $\begin{array}{c}\text { Ayuntamiento } \\
\text { de Barcelona }\end{array}$ & 34.410 .083 & 32.722 .411 & 41.188 .825 & $0^{*}$ & 25.897 .339 & 14.567 .184 \\
\hline Total & 38.925 .783 & 36.236 .875 & 42.688 .825 & 1.500 .000 & 27.397 .339 & 16.067 .184 \\
\hline
\end{tabular}

Fonte: CONSORCI D'EDUCACIÓ DE BARCELONA (2012 - 2016).

* Foram destinados 9.962.246 euros pelo Ayuntamiento no exercício de 2013, mas esse valor não foi base de cálculo da previsão orçamentária.

No que tange à execução do orçamento, a liquidação das receitas correntes apresentou-se, até o ano de 2014, coerente com a paridade contributiva dos dois órgãos. Entretanto, houve, em 2015, uma inversão entre as posições, na qual, o Ayuntamiento de Barcelona financiou o maior volume de despesas correntes, e não mais o governo da Generalitat, cenário dos primeiros anos. Embora o valor executado decresça ao longo dos anos, constata-se o incremento extraordinário no orçamento para liquidação. Considerando o ano de 2010, o CEB gastou $75 \%$ a mais do previsto e, no ano de 2015, a dotação inicial foi de 16.067.184 euros, com execução de 23.811.642 euros. Esse desequilíbrio deve-se à contribuição extraordinária recorrente do Ayuntamiento de Barcelona, prática justificada pelos gestores Albert, Berta Argany e Ignasi Fernández como uma estratégia do governo municipal para obter reconhecimento político. Ou seja, a liberdade no empenho de recursos a cada novo programa garante ao governo municipal visibilidade e liderança política, limitando a capacidade de execução dos objetivos do CEB:

\footnotetext{
Nossos recursos são dependentes de conversa e negociação, então, não temos orçamento que nos permita planejar a manutenção e melhora dos edifícios a longo prazo. Fazemos auditoria para saber o estado dos edifícios e apresentamos aos governos, que definem quanto cada um pode oferecer [...] depende do interesse e disposição deles em investirem, e não há contratos de programas, mas aprovação dos recursos destinados a cada novo programa. (entrevista, concedida por Argany em 25/04/2016).
}

Essa condição é corroborada por Anglada, representante da área de serviços de Educação e Território do CEB, que complementou que essas negociações pontuais de se e quanto as administrações irão contribuir não seguem 
critérios de paridade ou percentual de contribuição, deixando pouca margem de gastos para novos projetos, já que o maior percentual está comprometido com despesas fixas.

Esse contexto também pode ser ilustrado pela decisão do município de não transferir a gestão de sua rede municipal para o CEB por questões políticas. Para Argany, entendeu-se que era melhor manter os ganhos desse investimento no âmbito municipal, principalmente em termos de reconhecimento do cidadão, o que em sua visão implica problemas. No plano pedagógico, não há uma definição conjunta entre o plano de trabalho das escolas bressole as escolas municipais, mas um trabalho de continuidade, no nível territorial, para estabelecer coerência entre as duas redes. Outro ponto refere-se à programas das escolas de música que não passam pelo consórcio.

A definição e aprovação do orçamento deve ocorrer até o dia 31 de dezembro. No primeiro trimestre de cada ano, a gerência do CEB apresenta ao Conselho de Direção o demonstrativo de liquidação do orçamento do ano anterior. A gestão financeira da entidade deve respeitar as disposições vigentes ao regime jurídico aplicável à Generalitat, atendendo às normas de contabilidade pública. Em relação aos mecanismos de controle, são realizados por intermédio de auditorias sob a supervisão da Intervenció General de la Generalitat ${ }^{\circledR}$, que apresenta um relatório à Intervenció Municipal.

\section{GESTÃO DE RECURSOS HUMANOS}

Entre as competências do CEB, destaca-se a gestão e coordenação das atividades desempenhadas por profissionais da educação e pessoal administrativo. O acordado foi manter o regime de contratação dos profissionais, preservando os direitos laborais, salários, benefícios, mesmo depois de sua contratação pelo consórcio, já que permanecem com o vínculo trabalhista com os governos municipal ou autônomo. No início da gestão, foram considerados todos os profissionais que, nos órgãos de origem, atuavam em setores vinculados à educação (preferencialmente com interface com o município de Barcelona). O primeiro ano envolveu um processo de acomodação desses profissionais ao novo modelo, identificação dos perfis adequados às tarefas e, ainda, a realocação de profissionais que, por diversas razões - incluindo preferências pessoais - desejaram permanecer nos órgãos em que trabalhavam. 
Tanto docentes quanto profissionais responsáveis pelas tarefas administrativas permaneceram vinculados aos governos de origem, e aqueles que prestam serviços diretamente ao CEB, são "cedidos" e incluídos na folha de pagamento da entidade. Em relação aos docentes, apenas uma pequena parcela está incluída na folha de pagamento do consórcio; entretanto, o CEB é quem trata de todos os demais trâmites (acompanhamento de faltas, formação, remanejamento e apoio).

Os profissionais oriundos do Ayuntamiento de Barcelona correspondem à maior parcela de profissionais remunerados diretamente pelo consórcio, ou seja, os valores referentes ao pagamento das despesas com pessoal são repassados pelo Ayuntamiento de Barcelona (governo municipal) ao CEB. Entretanto, os profissionais não incluídos na folha são, quase na totalidade, oriundos da Generalitat. Esse cenário, na visão da gerência do CEB, trata-se de um ponto ainda "não resolvido", na medida em que se idealizava, desde o início da composição do CEB, a gestão plena desses profissionais pelo consórcio.

Como o CEB não possui funcionários contratados diretamente, a substituição de profissionais segue a lógica de acompanhar o perfil dos profissionais das duas administrações, por meio de cessão de pessoal e processos seletivos internos. A respeito dessa convivência de profissionais de origens distintas, a gerente do consórcio mencionou:

Quando a nova Presidente [do CEB] assumiu, em uma reunião com os funcionários, ela pediu que eles se apresentassem. Foi comum ouvir: - Eu sou da Generalitat. Eu sou do Aynntamiento. Depois disso, ela fez uma intervenção, defendendo que independente da origem contratual, todos são do consórcio e que não deve existir essa separação. (entrevista, concedida por Argany em 25/04/2016).

Portanto, convivem dois regimes de contratação, com condições de remuneração distintas. Foram conduzidas reuniões com representantes dos trabalhadores e sindicatos para buscar equilíbrio salarial, benefícios e carga laboral entre os regimes, mas, conforme Maria Jesús Mier Albert, Presidente do Conselho de Direção do consórcio “[...] avançamos [...], mas ainda não conseguimos chegar a um ponto comum e será difícil, porque em qualquer negociação eles estão direcionados a chegar à melhor condição dos dois regimes, e isso, fica muito difícil" (entrevista, concedida por Albert em 12/05/2016). Apesar desse desajuste, a entidade aprovou uma espécie de Plano de Carreira ${ }^{9}$ que orienta a seleção dos recursos humanos e o desenvolvimento dos postos de trabalho (CONSORCI D’EDUCACIÓ DE BARCELONA, 2012-2016). 


\section{AÇÕES CONCRETAS PARA A GESTÃO COMPARTILHADA DAS REDES DE ENSINO}

A sede do consórcio está localizada na região central do município de Barcelona, e embora a sede ofereça atendimento ao público, o apoio para os serviços educacionais, como auxílio na busca por vagas e merenda escolar é descentralizado, com exceção de situações pontuais e campanhas específicas.

Quanto aos espaços consultivos e de participação da comunidade escolar que fazem interface com o CMB, os Conselhos Distritais ${ }^{10}$ e o Consell Escolar Municipal de Barcelona ${ }^{11}$, que representam a comunidade escolar da cidade de Barcelona, tiveram seus membros incorporados no corpo representativo do CEB, de modo a garantir alinhamento entre as deliberações (GENERALITAT DE CATALUNYA, 2005). Além desses espaços, o consórcio gerencia o Blog "Nós fazemos escola em Barcelona"12, que disponibiliza aos centros educativos um espaço de compartilhamento de iniciativas, experiências e opiniões, além de uma conta no Twitter que serve como um canal de difusão de informações, notícias e serviços.

Uma das atribuições do CEB é tratar do planejamento do Mapa Escolar, documento que prevê a organização territorial dos centros educacionais e a distribuição das vagas. O município de Barcelona, antes da criação do CEB, já se organizava territorialmente em dez distritos, e contava com o conceito de "áreas de influência" para a distribuição das vagas. As áreas de influência delimitam uma zona de proximidade dos centros a partir do local de residência da família, facilitando o acesso às escolas. Ocorre que a definição do mapa se fazia "a olho", conforme destacou Masó, representante da área de serviços de Educação e Território do CEB, o que no caso de um município populoso como Barcelona, gerava sobreposição, superposição de escolas, excesso ou falta de vagas em distritos.

Diante disso, inaugurou-se, em 2005, um processo mais dinâmico de distribuição das escolas/vagas, baseado em critérios objetivos, tomando como referência a posição do domićlio da família. Esse critério considera que em cada "ilha de casas" (ou quarteirão), cada família deve ter pelo menos três opções de

10 Cada distrito conta com um Consell Municipal de Districte, órgão de representação coletiva integrado por 19 conselheiros nomeados pelo Alcade.

11 O órgão pode solicitar informações sobre qualquer matéria que afete o campo da educação, propor projetos e emitir relatórios, com base na atuação de Comissões diversas (Participação, Subcomissão de Educação e Subcomissão de pais e alunos, Serviços Educacionais e relação escola-território, Escolaridade e Diversidade e Desenho Escolar e Matrícula). 
escolas para matrícula. Para tanto, o consórcio passou a acompanhar mensalmente os empadronamientos ${ }^{13}$ e o perfil de moradia, para então, definir as mudanças para o próximo ciclo.

Isso colocou em primeiro plano a distribuição das escolas a partir de uma lógica microscópica do município. Além da melhora da garantia de vaga aos alunos em local próximo à residência, reduziu-se o acúmulo ou déficit de escolas em alguns distritos. $\mathrm{O}$ gestor ainda menciona que esse processo de inscrição e matrícula envolve anualmente a análise a posteriori de fatores como escolas novas, cobertura - em função das mudanças demográficas, que podem variar em função de aspectos socioeconômicos, imigratórios, crescimento - e, ainda, as solicitações, reclamações e comunicações das famílias a respeito da vaga atribuída, por meio de formulários, cartas, visitas coletivas aos centros, canal web, bem como atendimento nos distritos durante três dias posteriores à inscrição.

\section{CONSIDERAÇÕES FINAIS}

A partir do estudo de caso, foi possível observar que a gestão compartilhada permitiu ao município de Barcelona imprimir no âmbito do planejamento educacional aspectos relacionados às especificidades escolares, por exemplo, na definição do Mapa escolar, que adota como critério o fator proximidade para a distribuição dos centros educacionais, com base em ferramentas de controle e acompanhamento do local de residência das famílias. Isso permitiu o planejamento integrado dos centros educacionais de titularidade dos dois governos, representando ganhos em termos de cobertura da rede.

Apesar disso, em termos de capacidade de gestão, a gestão financeira do CEB tem implicado deficiências, já que em detrimento do desenho e implementação de programas conjuntos, tem atendido a demandas dos dois governos mediante a disponibilidade de receitas. As consequências dessa prática têm levado os gestores a reconhecer que o consórcio possui pouca capacidade de intervenção, que se reflete na ausência de programas próprios, o que tem duas possíveis implicações: reduzida inovação e inviabilidade de ações de longo prazo.

Quanto ao processo de constituição do CEB, destaca-se que a efetivação da gestão compartilhada envolveu um período de planejamento e preparação para a execução do novo modelo, permitindo que se estabelecessem acordos acerca da distribuição territorial das escolas, formação das equipes, identificação e integração dos profissionais e, ainda, a adaptação das estruturas organizacionais em funcionamento. Isso leva a crer que, além de consenso entre os atores para 
a definição do formato legal de entidades dessa natureza, a constituição de consórcios que implicam o encerramento de organizações preexistentes, dotadas de rotinas organizacionais, contratos, culturas e recursos, demanda tempo e esforço das partes envolvidas; nesse caso, de atores representativos de dois governos.

Ainda assim, o rompimento com estruturas e instituições pré-existentes pode não ocorrer, em função de interesses políticos e corporativos. Algumas constatações ilustram esse argumento: a manutenção da rede de escolas bressol no município de Barcelona e a não transferência da folha de pagamento por parte da Generalitat. Essas situações podem ser interpretadas como consequência das preferências políticas dos governos, seja garantindo o reconhecimento da comunidade escolar de um serviço escolar exclusivo do município ou a defesa de um governo de não compartilhar poder financeiro a outrem para não distribuir poder político. Contudo, uma justificativa proeminente é a de que os dois governos mantêm-se em um "cabo de força", usando a retenção de parte de sua estrutura educacional como justificativa para a retenção do outro, sem, contudo, chegarem a um consenso.

A integração de duas redes de ensino também apresentou como desafio a convivência de dois regimes de contratação dos profissionais: há diferenças de carga laboral, benefícios e remuneração, implicando conflitos organizacionais. Essa integração também foi conflituosa no campo da identidade organizacional, já que, passados oito anos de gestão, funcionários não se identificam como "Consórcio", mas como "Ayuntamiento ou Generalitat".

No que se refere aos objetivos da integração dos governos na gestão da educação, constatou-se que, embora o consorciamento seja comumente um instrumento que permite economia e ganhos de escala em termos financeiros, a questão orçamentária não foi, no caso do $\mathrm{CEB}$, um ponto relevante para sua constituição. Além de o consórcio ter-se constituído antes do contexto de crise no espaço europeu (meados de 2009), o município de Barcelona, por intermédio do Ayuntamiento, já ofertava, de forma complementar e voluntária, uma rede de ensino própria, o que ilustra sua capacidade orçamentária para a oferta de serviços educacionais.

Ainda no âmbito da gestão, o fato de o Conselho de Direção ser composto por representantes dos dois governos pode levar a uma interpretação de que os processos de tomada de decisão são morosos e conflituosos. Entretanto, não se evidenciaram conflitos oriundos de divergências políticas que impliquem em bloqueio de ações, interrupção de programas ou inoperância. O Conselho, apesar de composto por profissionais indicados, apresenta estabilidade, sinalizando que mudanças políticas não têm implicado turn-over dos funcionários. Esse aspecto 
é importante porque a convivência duradoura implica a necessidade de diálogo recorrente entre os pares e seu exercício permite a construção de relações interpessoais de confiabilidade e aprendizado, facilitando os consensos (FEIOCK, 2013).

A esse respeito, observou-se, inclusive, que a estrutura do CEB não bloqueia a interferência de questões políticas, mas que o papel exercido pelo Conselho de Administração, por intermédio de uma gerência com caráter técnico, permite o reconhecimento de resistências políticas e, assim, a proposição de adaptações nas matérias a serem votadas, quando necessário. Portanto, não significa que os interesses políticos não existam, mas que se privilegiam aspectos técnicos em detrimento de barreiras que eventualmente se estabeleçam.

Apesar das dificuldades na integração das duas redes, partindo de uma herança administrativa, a entidade tem buscado um formato próprio e, embora este estudo tenha permitido constatar limitações do consórcio para implementar programas e políticas públicas, a atuação conjunta tem permitido a conjunção das potencialidades dos dois níveis de governo. De um lado, o conhecimento e experiência institucional da Generalitat, que já contava com uma estrutura burocratizada de gestão, dotada de quadros técnicos especializados e áreas funcionais já desenvolvidas para a educação. De outro, o Ayuntamiento, dotado de uma relação mais próxima com a comunidade escolar, maior domínio dos aspectos micro do território com suas particularidades. Isso permitiu ao CEB ser um instrumento de gestão que otimizou, entre outros aspectos, as capacidades institucionais dos governos autonômico e municipal.

Finalmente, resta como desafio para futuras pesquisas aprofundar aspectos em termos de escala, desempenho escolar e melhoria da qualidade dos serviços oferecidos a partir da cogestão. Os dados obtidos por meio dos documentos e entrevistas não permitiram constatar aspectos relevantes e concretos a esse respeito. Os gestores, quando questionados, destacaram que se trata de um momento de fortalecimento institucional do consórcio, no qual não foi feito esforço para mensurar o impacto das mudanças no processo de gestão da rede escolar ofertada no município de Barcelona na melhoria no desempenho dos alunos, mas que se vislumbra que essa melhoria será processual, à medida que os processos de gestão de aperfeiçoem. 


\section{REFERÊNCIAS}

ABICALIL, C.A. Sistema Nacional de Educação: os arranjos na cooperação, parceria e cobiça sobre o Fundo Público na educação básica. Educação e Sociedade, Campinas, v.34, no 124, p. 803-828, jul.-set., 2013.

ABRUCIO, F. L. Associativismo territorial para a coordenação intergovernamental in ABRUCIO, F. L.; RAMOS, M. N. Regime de colaboração e associativismo territorial; arranjos de desenvolvimento da educação. São Paulo: Fundação Santillana, 2012, p. 7-30.

ARAÚJO, G. C. Federalismo cooperativo e arranjos de desenvolvimento da educação: o atalho silencioso do empresariado para a definição e regulamentação do regime de cooperação. Revista Brasileira de Política e administração da educação. Associação Nacional de Política e Administração da Educação. Recife, 2012, v.28, n.2, mai.- ago. p. 515-534, 2012.

BLASCO, M. La cooperación interadministrativa: el Consorcio de Educación de Barcelona. In: VII Congreso Internacional del CLAD sobre la Reforma del Estado y de la Administración Pública Anais... Lisboa, Portugal, 8-11 Oct. 2002. Disponível em: <http://unpan1.un.org/intradoc/groups/public/ documents/CLAD/clad0043614.pdf>. Acesso em: 15 de março de 2016.

BOLLEYER, N. Intergovernmental cooperation: rational choice in federal systems and beyond. Comparative politcs. New York: Oxford Univesity Press, 2009.

CALDAS, E. de L. Formação de agendas governamentais local: o caso dos consórcios intermunicipais. 2007, 227p.. Tese (Doutorado em Ciência Política) Universidade de São Paulo, São Paulo, 2007.

CARNEIRO, J. M. B.; DILL, G. Arranjos federativos regionais na Alemanha e o papel articulador dos Landkreise. In: Cadernos Adenauer IV. Municípios e estados: experiências com arranjos cooperativos. Rio de Janeiro: Fundação Konrad Adenauer, abr. 2012, p. 57-76. 
CONSORCI D'EDUCACIÓ DE BARCELONA. El Consorci d'Educació de Barcelona: el nostre compromís amb l'educació de la ciutat. Barcelona, 2009. Disponível em: <https://www.edubcn.cat/rcs_gene/extra/documents/ inauguracio_seu/Compromis\%20CEB\%20BCN\%20260309.pdf> Acesso em: 22 de novembro de 2018.

CONSORCI D’EDUCACIÓ DE BARCELONA. Memorias y documentos de referencia. Barcelona. 2012-2016.

CONSORCI D'EDUCACIÓ DE BARCELONA. Resolució sobre un acord del Consell de Direcció del Consorci d'Educació de Barcelona en matèria de personal. $n^{\circ}$ 6800, de 30 de janeiro de 2015.

CONSORCI D’EDUCACIÓ DE BARCELONA. Traspàs de la gestió dels centres educatius de la ciutat al Consorci d'Educació de Barcelona. Barcelona, 2009.

CONSORCI D'EDUCACIÓ DE BARCELONA. Compromisos del Consorci d'Educació amb l'educació de la ciutat. Barcelona, 2009.

FEIOCK, R. The Institutional Collective Action Framework. In: The Policy Studies Journal. Oxford, vol. 41, nº 3, p. 397-425, 2013.

GANZELI, P.; OLIVEIRA, P. Relações intergovernamentais na educação: fundos, convênios, consórcios públicos e arranjos de desenvolvimento da educação. In: Educação e Sociedade, vol.34 no 125 Campinas Oct./Dec., p.1031-1047, 2013.

GARRIDO, N. Inter-municipal cooperation in Spain: dealing with microscopic local government. In: HULST, R.; MONTFORT A. V. (Eds.). Inter-municipal cooperation in Europe. Springer: Netherlands, 2007, p. 169-192.

GENERALITAT DA CATALUNYA. Decret 20/2005, de 8 de febrer, pel qual es determina la composició del Consell Escolar Municipal de Barcelona. Diário Oficial número 4320, de 10 de fevereiro de 2005. Disponível em: <http:/ / www.upf.edu/sintesi/2005/df20.htm>. Acesso em: 02 de março de 2016. 
GENERALITAT DE CATALUNYA. Decret 84/2002, de 5 de febrer de 2002, de constitució del Consorci d'Educació de Barcelona. Disponível em: $<$ http://dogc.gencat.cat/ca/pdogc_canals_interns/pdogc_resultats_fitxa/?actio $\mathrm{n}=$ fitxa\&documentId=268081 $>$. Acesso em: 10 de agosto de 2016.

GENERALITAT DA CATALUNYA. Llei 22/1998, de 30 de desembre de 1998, de la Carta municipal de Barcelona. Disponível em: <https://www.boe. es/buscar/pdf/1999/BOE-A-1999-2518-consolidado.pdf>. Acesso em: 30 de dezembro de 2017.

HULST; R.; VAN MONTFORT A. (Eds). Comparative Analysis and Conclusion. In: HULST; Rudie; VAN MONTFORT A. Inter-municipal cooperation in Europe. Vrige Universit Amsterdam. Springer: Netherlands: 2007, p. 211- 238.

MOVIMENTO COLABORA. Quem somos. Página eletrônica. Disponível em: $<$ http://movimentocolabora.org.br/quem-somos/>. Acesso em: 10 de janeiro de 2017.

PRATES, Â. M. Q. Os consórcios públicos municipais no Brasil e a experiência europeia: alguns apontamentos para o desenvolvimento local. In: III Congresso Consad de Gestão Pública, 15-17 mar. 2010, Brasília. Anais ... Brasília: Conselho Nacional de Secretários de Estados de Administração. Disponível em: $<$ http://www.escoladegestao.pr.gov.br/arquivos/File/Material_\%20CONSAD/ paineis_III_congresso_consad/painel_1/os_consorcios_publicos_municipais_ no_brasil_e_a_experiencia_europeia_alguns_apontamentos_para_o_ desenvolvimento_local.pdf>.Acesso em: 30 de dezembro de 2017.

SOUZA, J, F. Redes de universidades: novos espaços de articulação no campo da educação superior pública brasileira. 2013; 148p. (Dissertação em Educação, Conhecimento e Inclusão Social) - Universidade Federal de Minas Gerais. Belo Horizonte, 2013.

STRELEC, T.C. Relações intergovernamentais no contexto educacional brasileiro: um estudo a partir dos acordos de cooperação nas políticas públicas em educação. Tese. 343 p. (Doutorado em Ciência Política) - Universidade Estadual de Campinas, Campinas, 2017. 
STRELEC, T. C.; COSTA, V. M. F. Cooperação e articulação intergovernamental: classificação, características e formatos à luz da experiência brasileira. In: Revista Iberoamericana de Estudios Municipales, no 14, ano VII, p. 37-62, 2016.

STRELEC, T.C. Desafios da adaptação institucional: um estudo do impacto da Lei de Consórcios Públicos no estado de São Paulo. 2011, 201 p.. Dissertação (Mestrado em Administração Pública e Governo) - Fundação Getúlio Vargas. São Paulo, 2011.

WILSON, R.; GAMKHAR, S. Cooperação e relações intergovernamentais nos governos locais: o caso dos Estados Unidos. In: Cadernos Adenauer IV. Municípios e estados: experiências com arranjos cooperativos. Rio de Janeiro: Fundação Konrad Adenauer, 2012, p. 31-56.

THAMARA CAROLINE STRELEC é doutora em Ciência Política pela Universidade Estadual de Campinas com estágio doutoral no lnstitut de Govern i Polítiques Públiques da Universidad Autònoma de Barcelona e Mestre em Administração Pública e Governo pela Escola Brasileira de Administração da Fundação Getúlio Vargas de São Paulo. E-mail: thamara.strelec@gvmail.br

VALERIANO MENDES FERREIRA COSTA é doutor em Sociologia (USP). Professor do Programa de Pós-Graduação em Ciência Política da Universidade Estadual de Campinas. E-mail: vmfc@unicamp.br

RAQUEL GALLEGO CALDERON é Ph.D. em Government (Ciência Política) e Máster em Public Administration e Public Policy pela London School of Economics and Political Science (LSE). Também é Máster em Ciência Política e Licenciada em Ciências Políticas e Sociologia pela Universitat Autònoma de Barcelona (UAB). Está acreditada como Catedrática por AQU-Catalunya (2010). Atualmente é Professora agregada no Departamento de Ciência Política e Direito Público e Investigadora no Instituto de Gobierno y Políticas públicas (IGOP). E-mail: raquel.gallego@uab.cat 